\title{
Disorders of Speech and Pronunciation and their relationship to Self-confidence among those Disturbed in Communication in the State of Kuwait
}

\section{Tarafa Muhammad Abdul Rahman Al Habib ${ }^{1}$}

Faculty of Basic Education, Public Authority for Applied Education and Training, Kuwait

\begin{abstract}
The research aims to achieve identify the relationship between speech disorders and selfconfidence in speech and pronounciation disorders. according to the gender variable and according to the academic grade variable in the State of Kuwait, The number of the research sample was (50) children with speech and pronunciation disorders, who were selected by a simple random method, Who were diagnosed according to their performance on the evidence for observing speech and pronunciation disorders, The researcher used the self-confidence scale prepared by Sydney Shrouj (1990) translated and Arabized by Adel Abdullah : 1990, and A guide for noticing speech and pronounciation disorders (prepared by Ibrahim El Shafei :2008), And the reseach reached out to there is a negative correlation between the sub-dimension, speech and pronounciation disorder and voice disorder as a sub-dimension with self-confidence, It is clear from the previous round that there are no differences in the relationship between speech and pronounciation disorders and self-confidence according to the gender variable, given that gender (male / female), and that there are no differences in the relationship between pronounciaion disorders and confidence according to the grade variable
\end{abstract}

Keywords:, Speech difficulties, Communicate, psychiatric disturbances, Self-esteem, Selfconfidence

$$
\begin{aligned}
& \text { ملخص } \\
& \text { يهدف البحث إلي التعرف علي العلاقة بين اضطرابات النطق والكلام والثقة بالنفس لدى مضطربي النطق والكلام طبقا } \\
& \text { لمتغير النوع والصف الدراسي في دولة الكويت ، وبلغ عدد افراد عينة البحث (50) طفلا وطفلة من مضطربي النطق والكلام } \\
& \text { تم اختيارهم بالطريقة العشوائية البسيطة ممن تم تثخيصهم وفقا لأدائهم علي دليل ملاحظة اضطرابات النطق والكلام }
\end{aligned}
$$

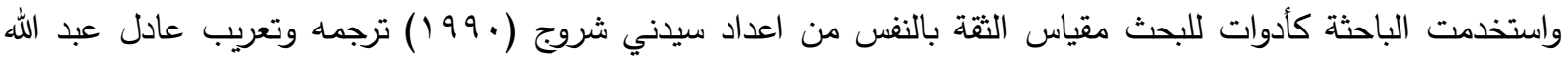

$$
\begin{aligned}
& \text { (1990) ودليل ملاحظه اضرابات النطق والكلام (اعداد ابراهيم الثافعي 2008) وتوصلت البحث الي وجود علاقة ارتباطية } \\
& \text { سالبة بين البعد الفرعي واضطراب النطق والكلام و اضطراب الصوت وبين الثقة بالنفس لا توجد فروق في العلاقة بين }
\end{aligned}
$$




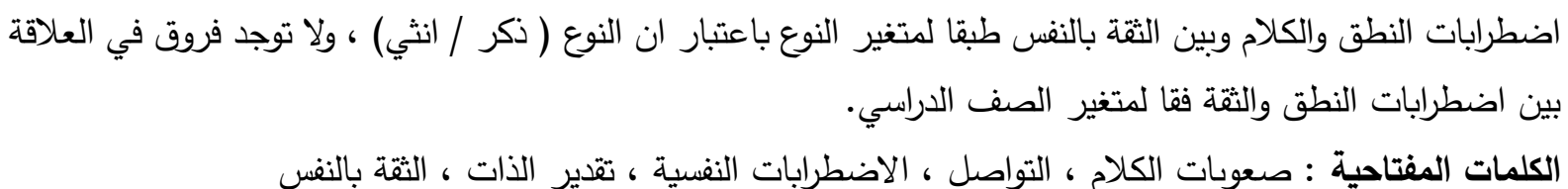

Introduction

Speech or oral language, is the main means of interaction and communication with others, speech is an ability that God gave it only to humans Speech needs to produce a set of complex processes that depend on the individual's organic speech organs, as well as his safety from the obstacles that effect the production of speech and its proper access to it. The listener to communicate through speech, Some individuals in different societies, at different ages, norms and gender suffer from speech disorders such as rattle and stinging of all kinds, including disability of pronuncied theletter "S" and "R" and vision, speed of speech and beetle, which would contribute to impeding the individual from performing some of his multiple roles in his social context of community (AlJayousi , 2002)

Language and speech are the mental mechanism by which information and knowledge are stored and mental images transformed into symbols and connotations. It is a tool for processing and thinking for a person in all the thoughts and feelings and interests in his mind, as well as achieving communication between members of society and by means of which the process of social integration is achieved. The process of learning and teaching takes place, and it represents for any society a central part of its cultural and civilizational identity

Communication through speech plays an essential role in a person's life

. A person starts from satisfying his natural needs and ending with his self-esteem. However, self-esteem can only be achieved through interaction with others in the family, school, or comrades group.A person with speech disorders usually suffers from psychological disorders such as anxiety, a feeling of social inadmissibility, lack of selfconfidence, a sense of shame, and a feeling of inferiority, which generates a sense of isolation and introversion accompanied by psychological tension, but despite this there are some cases of speech disorder that stand up to the challenge of pathological and outlook Social and motivation for the individual to exert more effort and exercise challenge until he becomes superior to his colleagues. (Al- Dabbous, 2004)

Likewise, both self-confidence and selfesteem have an important role in an individual's life, as they are important factors in practicing life and overcoming all difficulties encountered by a person, given that self-confidence is the extent to which the individual perceives his competence, skills, and psychological, physical, social and linguistic abilities through which he deals effectively with different situations. That he is exposed to in his life

The relationship between speech disorders and some personal properties such as selfconfidence is important, which makes it a subject of study and considering this topic has not been studied with great care and attention, and this is what led to the difficulty of research due to the lack of references in the State of Kuwait, so the researcher tries in this search for speech disorders and its relationship to self-confidence among students Adolescents, while illuminating important aspects of their lives

\section{Research problem}

Speech is the most important means of an individual's communication with others, through which the individual expresses himself and his needs that he wishes to his satisfication. Man is distinguished from other creatures by his ability to communicate through speech between himself and others, so any defect that affects this function hinders his communication with others, what may It often leads a person to be vulnerable to some psychological disorders that would impede the individual from completing his pursuit of achieving his personal and social 
compatibility in life.Research on speech disorders requires knowledge of their causes and the factors affecting them, and among these factors and variables are emotional psychological factros such as the individual's concept of himself and the extent of his linguistic competence and his general competence, anxiety and tension from speaking in front of others, which is called Speech phobia of course researchers are disagree with which of this factors is the cause and which of them are the most important The result hence the question remains without a definitive answer, which is: Are speech disorders caused by multiple factors, including psychological factors, or are the psychological variables in the verbal disorder of the individual resulting from this disorder?

By looking at the results of previous studies, we notice a clear contradiction between them, as several studies have concluded that there is a relationship between selfconfidence in the school stage, as we see that it varied between them according to their topics and goals. On the objective side, we find that it focused on one form of speech disorders forms, which is disturbed speech disorder, and it was not interested in studying the rest of the forms.

Based on these studies, the researcher wanted to clarify most of the forms of speech disorders that are common in adolescence and their relationship to self-confidence. Considering that this stage is one of the most important stages that a person goes through , By answering the following question

\section{Search Hypotheses}

1- The current research tries to answer the following questions:

There is a statistically significant correlation relationship between speech and pronunciation disorders and self-confidence in a group of speech impaired children in Kuwait is that

2- then is statistically significant correlation between speech and pronunciation disorders and self-confidence according to the gender variable among a group of speech impaired children in Kuwait
3- there is no statistically significant correlation relation between speech and pronunciation disorders and selfconfidence according to the level grade "seventh - ninth"of a group of children with disturbed speech of Kuwait

\section{Research aims}

The research aims are to achieve the following:

1- Identifying the relationship between speech disorders and self-confidence in speech and pronunciation disorders in the State of Kuwait

2- Knowing the relationship between speech disorders and self-confidence in speech and pronunciation disorders according to the childern puplies gender in Kuwait

3- Identifying the relationship between speech disorders and self-confidence in speech and pronunciation disorders according to the puplies grade in the State of Kuwait

\section{Research importance}

1- Clarifying speech disorders and their negative impact on the level of selfconfidence in speech

2- It deals with the phenomenon of speech and pronunciation disorder as one of the most common communication disorders affecting children

3- The importance of research is due to the importance of childhood and the importance of caring for this stage as an important stage in human life.

4- It deals with an important phenomenon speech disorders that reflects negative effects on society resempled in selfconfidence

\section{Research concepts}

- Self-confidence

A personal trait with which the individual feels the competence and the ability to face punishment and difference problems, using the maximum of his capabilities and abilities to achieve his desired goals. It is a positive way of thinking, feeling and behavior that works to encourage normal psychological growth to reach the required level of 
psychological health and psychological and social adjustment,. In the manifestations of the kinetic production of speech or the inability to produce, specific verbal sounds and the result of errors in the output of speech letter sounds from the outside and not being correctly formed (Qawasma \& Al-Farah 1996, 37)

- Disorders of speech and Articulation It refers to any defect in the normal performance, for any process of speech and Articulation or an unusual defect, or deviation from the normal, or distortion, all of which are used to describe the process of inconsistency and disagreement. (ALshakhs, 1997)

\section{Theoretical framework,}

\section{- Speech and pronunciation disorders} Concept of speech

Speech is the means of communication through phonemic symbols, and through it the individual can express his thoughts and feelings and understand the feelings of others who use linguistic symbols, which is a kinetic activity of breathing, voting, articulation or vocal resonance (Al-Zureikat 2005, 22)

\section{- Concept of speech and pronunciation}

\section{$\angle$ disorders}

Speech disorders are defined as a marked disturbance in speech or voice, verbal fluency, linguistic delay or failure to develop expressive or receptive language, which makes the child in need to special treatment or educational programs. So,that the following conditions are met:

- Error in sending or receiving messages.

- If this error affected the person, educationally or socially.

- If this difficulty affects the individual's interaction with others, then they will be negative towards him.

And these disorders are common between young and old, and they occur mostly in young people as a result of mistakes in the letters exits, and not pronouncing them correctly. The degrees of speech vary from simple lisping to acute disturbance, where speech is incomprehensible as a result of deletion, substitution and distortion, and it may occur in some adults as a result of injury to the central nervous system and this leads to the production of speech with difficulty or effortlessly (A1-Rashidi 1975, 6)

Linking speech to speech disorder about the acceptable range in the individual's environment, and describing him in one of theier indicators:

- Difficulty hearing.

- Lack of clarity

- It is associated with inappropriate audio and visual characteristics

- Not suitable for age, gender and physical development

- Stress in production of voices

- Disturbance in the production of certain sounds

- Defects in rhythm and tone

- Disruption of voice production and loneliness

(Al-Zureikat 2005, 22)

- The difference between language disorder and speech disorder

- There are differences between Language disorder and speech disorder, as communication disorder is characterized by a language disorder, so it is necessary to distinguish between speech disorder and language disorder, as there are different reasons for each of them and each of them requires different therapeutic interventions

- Speech disorder is a disorder that affects pronunciation, voice, or fluency, while language disorder is a disability or deviation that affects the understanding, use and production of spoken language, written language, or a verbal symbolic communication system.

- Pronunciation disorder is a problem or difficulty in issuing the necessary sounds to speak in the correct way, it is the suffering of some children from trouble pronunciation words

- As for language disorders, they are disorders related to the reception of language (understanding) or its 
expression, or disorders related to language communication

(Organizing one sentence after another).

- We conclude from the above that language disorders differ from speech disorder, as language disorder affects the understanding or production of pronuncied or written language, and pronunciation disorder affects speech or voice (Arar,2016, 7)

\section{- Manifestations of speech disorders}

\section{Distortion}

A distortion involves pronouncing the sound in a way that brings it closer to the normal sound, although it does not exactly match it, that is, it includes some mistakes, and the distortion is spread between young and old, and often appears in certain sounds such as the letters ( $\mathrm{s}, \mathrm{sh}$ ) where the (s) sound is pronounced accompanied by a long beep, or pronounced A sound (sh) from the side of the mouth and tongue, and some use the term lisping to refer to this type of pronunciation disorder.

This may happen as a result of tooth loss, or failure to put the tongue in its right position during speech, or deviation of the position of the teeth on the sides of the lower jaw, which makes the air go to the sides of the jaw and thus the child cannot pronounce sounds.

\section{(Faisal Al-Afif dt , 3)}

\section{Omission}

In this type of speech defect, the child omits one of the sounds contained in the word that Consequent, only part of the word is pronounced, and the deletion may include multiple sounds, and constantly becomes The child's speech in this case is not understood at all, even to people who would like Listening to him like parents and others, deletion defects tend to occur most frequently in young children More common than is observed among older children, these defects also tend to appear Pronunciation of consonants that lie at the end of a word, more than they appear in the beginning or middle of the consonants (Al-Jalameda 2016, 275)

\section{Addition}

This means that the individual describes a new letter to the pronuncied word, and the phenomenon of adding letters is considered normal until the age of entering school. Addition is the addition of the child some letters or sounds, so one sound is heard as if it is repeated (Al-Rashidi 1975, 5)

\section{Substitution}

Substitution is the child's replacement of a letter with another letter, the sound may be very similar to the other letter, and it is the most common disease in children, which leads to their lack of understanding (Madkour 2006, 160)

\section{Stuttering}

Stuttering is a functional disorder that affects the verbal rhythm and obstructs it, and is represented by verbal repetitions or pauses due to the intensity of air, where the breathing mechanism becomes inversely, or the child who suffers from stuttering takes air from the mouth instead of the nose. And stuttering is more than just a break in speech, which is known as lack of fluency, but rather is a communication problem that hinders the individual from performing the speech correctly and properly, due to the large number of interruptions during speech, which causes embarrassment and confusion to the sufferer, and brings him psychological damage. It is a complex problem that can be easily noticed, and a person who suffers from stuttering suffers from feelings of anxiety, shyness, confusion, and psychological maladjustment (Madi \& Qada 2014, 201)

\section{Aphasia}

It is a difficult speech disorder, which is often acquired in adulthood, in addition to its effect on the spoken language, it also causes problems and disturbances in understanding the speech of others, reading and writing. Aphasia is used as a general term to describe a number of separate syndromes. Failure in the ability to form, restore and decode language codes, and it may appear without prior warning in some individuals who do not suffer from previous language or speech disorders (Al-Zureikat ,2005, 278)

Likewise, it is the loss of the ability to speak at the appropriate time despite the individual 
knowing what he wants to say, which results from disease in the centers of the brain.

\section{( Abu Bakr, 2016, 41) Stammering}

It is a disorder in verbal fluency, a rate of speed accompanied by an incorrect breathing style, that leads to disharmony of the speech organs, appears in the form of pause or lengthening, or repetition of the voice, syllable or word, and has a psychological origin, leads to fear of speech and avoid it in certain situations

\section{( Alou ,2016, 46)}

Stuttering is considered a common defect, and it is a disorder in verbal fluency that appears in a pause or repetition of the voice or syllable. It is found in adults and children and in various societies. It may be the result of fear or shame.

\section{Self-confidence}

\section{The concept of self-confidence:}

Self-confidence undoubtedly includes the perceptual cognitive side and the behavioral aspect. The perceptual aspect is the individual's awareness of his competence and capabilities and his knowledge of the skills he has, with his knowledge of the limits of those capabilities and his acceptance of them. As for the behavioral aspect, it is about translating these positive beliefs about the self into behavioral actions and movement manifestations that reflect The extent of the individual's self-confidence through his ability to deal effectively, in coincide and harmony with the life situations he lives, meaning that self-confidence begins with positive beliefs about the self, followed by satisfaction and acceptance of it. So that this belief and this satisfaction turn into actions and behaviors, a phenomenon that reflects the individual's self-confidence.

Self-confidence is defined as "the individual's perception of his competence, skill and ability to deal effectively with different situations" ( Muhammad 1990, 5)

Likewise, it is the individual's perception of his capabilities, preparations, skills, experiences and competence in dealing with situations and events effectively and interest (Abdel Aal, 2006, p 7)
Self-confidence is also defined as "an important feature that represents a manifestation of an individual's mental health, and losing or weakening it leads the individual to withdrawing behavior, as a defensive response that the individual does to reduce the tension and anxiety he experiences as a result of his lack of it." (AlGhamdi 2009, 87)

Baggerly \& Max 2005 believes that there are five components of self-confidence:

1. looking at the self as capable, and believing in its ability to do things like others

2. Bullet $A$ sense of belonging, and the belief that it is an integral part with others.

3. Optimism for the future, and a positive outlook on life.

4. Facing failure by viewing failure experience as an opportunity to learn and grow in life.

5. Having appropriate sources of reinforcement through role models

\section{Manifestations of low self-confidence}

Low self-confidence is an interconnected chain that begins with a lack of selfconfidence, then the belief that others see its flaws and negatives, which leads to feelings of anxiety about that and fear of negative behavior, and this leads to a sense of shyness, which again leads to poor self-confidence, which means The destruction of an individual's life.

The manifestations of low self-confidence are as follows:

1- Feeling of powerlessness to face problems and dependence on others for ordinary matters.

2- The tendency to hesitate, back down, and be overly cautious.

3- Anxiety about behaviors and personal characteristics.

4- Sensitivity to social criticism, and suspicion of others' words and actions.

5- Fear of competing, resentment of defeat, feeling of a lack of merit, conformity for fear of criticism, and a feeling of shame, confusion, and shyness in new situations 
There are also some manifestations of a lack of self-confidence, as follows:

1- Self-centeredness.

2- Feeling dissatisfied with personal conditions and characteristics.

3- Feeling the need to get better.

4- Feelings of guilt and crying spells. (A1Washeili 2007, 25)

\section{Methodology}

The current research, which deals with the nature of the relationship of speech and pronunciation disorders with selfconfidence, so, the descriptive approach was used, which can be defined as. A method of analysis and interpretation in an organized scientific manner, in order to reach specific goals for a problem, and others see that the descriptive approach is a way to describe the proplem under study, and to quantify it by collecting information about the problem, classifying it, analyzing it and then subjecting it to careful study. (Bouhosh Wakher, 1999, 143)

\section{Statistics}

The researcher used the statistical program (SPSS) to process the data for this research using the following statistics:

- Pearson correlation coefficient

- Z.TEST

\section{Sample:}

The number of the research sample was (50) children with speech and pronunciation disorders, who were selected by a simple random method, who were diagnosed according to their performance on the evidence for observing speech and pronunciation disorders from the visitors to the Social Development Center in Al-Marqab and the Al-Nafisi Center in Al-Sabah Medical District, and the Child Training Center in Kuwait, half of them from Males and the second half of females with adjusting variables between them

\section{Tools}

1- A guide for noticing speech and pronunciation disorders (prepared by Ibrahim E1 Shafei 2008)

It is a guidance consisting of 26 phrases, expressing three types of speech and pronunciation disorders presented to the observer, and he must determine the degree of applicability of the phrase through three options (often, sometimes, rarely) and give each choice a score according to the direction of the phrase, so the positive direction is the estimate $(2,1,3)$ and calculated of scores for each sub-dimension.To verify from it, the list was presented to eight arbitrators, and some phrases were amended based on the comments of some of the arbitrators, and four phrases were deleted from the dimension of fluency because the arbitrators did not agree on them, so the list became composed of 25 phrases, all in the positive direction, and thus the highest degree is $3 \mathrm{X}$ $26=78$ ) indicates the highest degree of speech and pronunciation skill, and the lowest score 26 indicates the lowest degree of speech and pronunciation skill. The method of displaying the vocabulary was modified, so that all of them were in the positive direction instead of some being negative, and for further control the following procedure was followed. So that the author of the guidance and the teacher of arabic language and the supervisor of field education to notice some students from the third grade avarage sauids , it is mean two classes of a school in Bisha governorate, and the observed each student while he was talking.Each observer prepared a form separately for each student, then the forms were corrected, three scores were calculated for each student, then the correlation coefficient between every two of their these estimates was calculated, so the correlation coefficient between the three arbitrators 'scores for the sample (50 students) ranged between (0.79) and (0.96) It is a coefficient of high significance, and the internal coherence of the guidance was verified by calculating the correlation coefficients between degrees on the subdimensions with each other, as well as with the total score, which ranged from between (0.67) and (0.84) which are statistically significant rates at more level From (0.000).validity was also verified through Exploratory Factor Analysis and through the Principal Component Analysis and Varimax 
method, and it was concluded that there are three factors that together explain $(83.68 \%)$ of the total variance (the first factor $=$ $60.4 \%$ ), (the second factor $=12.19 \%$ ) and (the third factor $11.08 \%$ ), The function ramifications according to the Glyford criterion ( $\_$or +0.3$)$ ranged between $(0.64$ and 0.85 ), and the first factor represented the soundness of the pronunciation of sounds and the suitability of the sound to the position, and the second factor represented the tones of the voice and its relationship to the verbal position, and the third factor was fluency in speech and self-confidence. From the reliability by calculating the Alpha Cronbach coefficient for the subdimensions, and the total degree, the value ranged between (0.67 and 0.79$)$, which are values indicating the reliability of the high evidence, and the correlation coefficient between the two parts of the guidance was also calculated with the Gutmam equation Split-Half so the coefficient was after correction with Spearman Brown's equation equals (0.92), which is a significant coefficient at a level greater than (0.000)

\section{2- Self-confidence scale validity}

The researcher used the self-confidence scale prepared by Sydney Shrouj (1990) translated and Arabized by Adel Abdullah (1990)

The researcher presented the scale in its first form consisting of (55) paragraphs on ten experts and specialists in psychology and mental health to determine its apparent validity. The modifications were made that some of the arbitrators deemed necessary and they agreed on the scale paragraph after rephrasing some of them and deleting (5) paragraph so it became (48) Paragraph

\section{Reliblility}

In order to ensure the stability of the scale, the researcher conducted a test of the extent of the internal consistency of its paragraphs, as the coherence of the scale was evaluated by calculating the Alpha Cronbach coefficient, and despite the absence of standard rules regarding appropriate values, in practice Alpha is reasonable in educational research and it was a consistent result The measurement tool . which is a high and acceptable percentage, to carry out the analysis process to achieve the objectives of the study, and after confirming the validity of the scale and its reliability. it settled in its final form consists of 48 paragraphs reflect feelings and trends and types half of it are positive and the other half are negative and became valid for application. In front of each statement there are five options whose degrees range from $(1,2,3,4,5, \ldots)$ in positive expressions, while negative expressions have degrees ranging from $(1,2,3,4,5 \ldots)$

\section{Results}

The results of this research will be presented and expressed in the form of how they agree or disagreement with the theoretical frameworks and previous studies closely related to the research variables, as well as statistical methods to verify the results of the research.

\section{Results of the first hypothesis}

Which states: (There is a statistically significant correlation relationship between speech and pronunciation disorders and selfconfidence in a group of speech impaired children (in Kuwait). The researcher used the Pearson correlation coefficient to answer this hypothesis and the following table illustrates that 
Table 1: the correlation coefficients between speech and speech disorders and selfconfidence

\begin{tabular}{|l|l|l|l|l|}
\hline $\begin{array}{c}\text { pronunciation } \\
\text { disorder }\end{array}$ & $\begin{array}{c}\text { Fronunciation } \\
\text { disorder }\end{array}$ & Voice disorder & Fluency & $\begin{array}{c}\text { Speech and } \\
\text { pronunciation } \\
\text { disturbance } \\
\text { (total) }\end{array}$ \\
\hline Self-confidence & $0.24-$ & $019-$ & $0.02-$ & - \\
\hline
\end{tabular}

The table shows the values of the correlation coefficients between speech and pronunciation disorders and self-confidence. The correlation coefficient for the subdimension of pronunciation disorders (speech disorder and self-confidence) was ($0.24)$ which is a negative relationship and a statistically significant at the level of significance (0.01). This means that there is a negative correlation between the subdimension, speech and pronunciation disorder and self-confidence. it is also clear that there is a negative correlation relationship with statistical significance at the level (0.05) between voice disorder as a subdimension of speech and pronunciation disorders and self-confidence. There is no statistically significant relationship between the dimension of fluency and selfconfidence, also, there is a negative correlation at the level of significance (0.01) between the total number of speech and pronunciation disorders and self-confidence, which is a significant and negative relationship, which means that the more severe the speech and speech disorders, the lower the level of self-confidence and vice versa.

Interpretation of the results of the first hypothesis

The results of this research are in agreement with the results of many studies, for example, the study of (Al-Noubi 2010), which aimed to develop self-confidence among stutterers through aguidance program, and one of its most important results was the existence of a negative correlation between the degree of stuttering and the level of selfconfidence.The researcher see that one of the most common speech disorders, As well as, the study of (Haseeb Muhammad 2099), which tested the effectiveness of a guidance program to increase self-confidence and reduce stuttering, and one of the most important results of this study was the presence of a negative correlation with statistical significance between selfconfidence and stuttering disorder, as stuttering reduces self-confidence. There are many studies whose results are consistent with the results of the current research, which showed a significant negative relationship between speech and pronunciation disorders and self-confidence. In this regard, Tomas (2007) states that the individual who suffers from low selfconfidence may lose many chances of success due to being one of the risks that affecte him, as a result of his speech disorder.

There are many factors that control a person's self-confidence, including what is related to the person himself, in terms of his potentials and available capabilities, the integrity of his physical organs, and his enjoyment of mental health, and some of them are related to the environmental conditions that the individual lives, and the effects it contains on the psychological formation of the person, and the individual who suffers from a disorder or defect, suffers from a deficiency in carrying out the tasks of his daily life, and his disorder in verbal fluency reduces his ability to use speech in communicating with others, which will reflect negatively on him, so he avoids the interaction with others and communicating with them, which affects his psychological formation and self-confidence

( El-Ghatawneh 2013, 248) 
Results of the second hypothesis

Which says (there is no statistically significant correlational relationship between speech and pronunciation disorders and self- confidence according to the gender variable among a group of speech disorders children in (Kuwait) and the following table explains that.

Table $2:$ the difference in the relationship between speech and pronunciation /disorder and the level of self-confidence according to gender

\begin{tabular}{|c|c|c|c|c|c|c|}
\hline \multirow{2}{*}{ sample } & \multirow{2}{*}{ number } & \multirow{2}{*}{$\begin{array}{c}\text { Correlation } \\
\text { coefficient value }\end{array}$} & \multirow{2}{*}{$\begin{array}{l}\text { Fisher } \\
\text { standard } \\
\text { value }\end{array}$} & \multicolumn{2}{|c|}{$\mathrm{Z}$. test } & \multirow{2}{*}{$\begin{array}{c}\text { Indication } \\
\text { level }\end{array}$} \\
\hline & & & & Calculated & Tabulated & \\
\hline Males & 25 & 0.756 & 0.986 & \multirow[b]{2}{*}{0.163} & \multirow[b]{2}{*}{1.96} & \multirow[t]{2}{*}{ Not d } \\
\hline Female & 25 & 0.794 & 1.083 & & & \\
\hline
\end{tabular}

It is clear from table (2) that there are no differences in the relationship between speech and pronunciation disorders and selfconfidence according to gender, given that gender (males / females) speech and pronunciation disorders does not affect their level of childern who have self-confidence.

Interpretation of the results of the second hypothesis

The overall results of this hypothesis are that gender (male / female) have disturbed speech and pronunciation does not affect their level of self-confidence, and this result is in agreement with the results of many studies, for example the study (Sabra, 2018), who aimed to reveal differences in confidence Self-confidence according to the gender variable, and among its results was that there are no statistically significant differences between males and females on the scale of self-confidence, As well as, a study (Sherik 2017) that tested self-confidence and its relationship to motivation to learn, and whose results confirmed the absence of statistically significant differences in the level of self-confidence among students of the College of Education at the University of Mosul according to gender .

This may be due to the similarity in many matters, including methods of social upbringing, and contemporary society and view of the equal status between males and females, and in the current research, the similarity between them in the severity of disability (speech disorder) contributes to the low level of self-confidence.

\section{Results of the third hypothesis}

Which states (There is no statistically significant correlational relationship between speech and pronunciation disorders and selfconfidence according to the grade level "seventh - ninth" in a group of children with disturbed speech in (Kuwait) and the following table explains that.

Table 3: Difference in the relationship between speech and pronunciation disorders and self-confidence according to the grade variable (seventh - ninth)

\begin{tabular}{|c|c|c|c|c|c|c|}
\hline & number & \multirow{2}{*}{$\begin{array}{c}\text { Correlation } \\
\text { coefficient } \\
\text { value }\end{array}$} & $\begin{array}{c}\text { Fisher } \\
\text { standard } \\
\text { value }\end{array}$ & Calculated & Tabulated & Indication \\
& & level & Z. test \\
\hline $\begin{array}{c}\text { Intermediate } \\
\text { first grade }\end{array}$ & 25 & 0.739 & 0.948 & \multirow{2}{*}{0.071} & 1.96 & Not d \\
\hline $\begin{array}{c}\text { Third grade } \\
\text { average }\end{array}$ & 25 & 0.787 & 1.062 & & & \\
\hline
\end{tabular}


It is clear from the previous table that there are no differences in the relationship between speech disorders and confidence according to the grade level (first average - third average)

\section{Interpretation of the third hypothesis}

This result is in correspond with the results of the study (Ender, 1985), which did not show statistically significant differences between students in the level of selfconfidence according to the grade variable, and if third-grade students were more confident than second-grade students, As well as the study (Al-Rikabi ,2000) that reached the same result did not show any differences in the level of self-confidence according to specialization and the academic year.

From the researcher's point of view, the reason for this may be that the research sample is in one age group (11-15) years, which is the special stage of the psychosocial development stages called the sense of the hobby, which is the harvest stage of what the parents and the school planted in the child. The elementary stage and moved to the higher stage, and his personality features have appeared, so if he was confused for any reason, he appeared shy, introverted and lost confidence in himself, and he could not answer the question even if he knew the answer of that question, he would still disable to raise his hand to ask about something difficult for him. In addition to his shyness of confronting people and not feeling self-respect, but if he is confident in himself, he can rely on it in the face of difficulties (Abdel Moati, 1999) 


\section{References}

1. Abdel Aal, Mohamed (2006) Social skills and their relationship to self-confidence and job satisfaction among a sample of primary school teachers, Journal of the College of Education, Mansoura, part four, No. 60

2. Abdel-Mo'ti, Hassan . Kenawy Hoda (1999) The Psychology of Growth, Qebaa House for Printing, Publishing and Distribution, Cairo

3. Aboubakr, Najia (2016) Investing theories of Psychology in Treating Constructivist Speech Diseases, Piaget Model, Master Thesis, University of Bejaia, Algeria

4. Al-Afif, Faisal (D.D.) Speech and Language Disorders, Arab Book Library, Jeddah, Saudi Arabia

5. Al-Dabbous, Rana Suhaim (2004): stuttering and its relationship to academic achievement and self-concept, a comparative study in late childhood. A magister message that is not published. Cairo: Faculty of Arts, Ain Shams University.

6. Al-Enezi Saud Shaish (2003) Self-confidence and motivation for achievement among outstanding and ordinary students in middle school in Arar. A Master that is not published. Makkah Al-Mukarramah Ja: Ma'at Umm al-Qura

7. Al-Ghamdi, Salih Yahya Al-Jarallah (2009) Speech disorder and its relationship to selfconfidence and self-esteem among a sample of middle school students, PhD thesis, Umm Al-Qura University, Saudi Arabia

8. Al-Jalamda , Fawzia Abdullah (2016) Effectiveness of a Training Program in Early Intervention for the Treatment of Speech Disorders in Children with Mental Disabilities in the Kingdom of Saudi Arabia, Journal of Psychological Counseling, Ain Shams University, Issue (47), Vol. (1)

9. Al-Jayyousi, Mohamed Bilal (2002) You and I (Introduction to Human Communication Skills) Riyadh: Arab Bureau of Education for the Gulf States

10. Al-Noubi , Sohair Muhammad (2010) Developing Self-Confidence Using the Techniques of Linguistic and Neural Programming and Cognitive-Behavioral Therapy, PhD Thesis, College of Education, Ain Shams University

11. Alou, Fatima (2016) Linguistic disorders and the issue of communication among the primary stage child, master's thesis, Abi Bakr Belkaid University, Algeria
12. Al-Qatawneh, Yehia Hussein (2013) revives the effectiveness of a training program to treat stuttering and its effect on the level of self-confidence, Taibah University, Madinah

13. Al-Rashidi Samihan (1975) Speech and Language and Speech Disorder, An Advanced Lean Learning System, King Faisal University, Saudi Arabia

14. Al-Rikabi , Nidal Abdul-Hasan (2000) The level of ambition and its relationship to selfconfidence among students of the College of Education, Al-Mustansiriya University, Master Thesis, The Culture Foundation Press, Baghdad-Iraq

15. Al-shakhs, Abdul Aziz Al-Sayyid (1997) Speech and Speech Disorders, Golden Pages Company Ltd., Riyadh, first edition

16. Al-Taie, Yahya . Ghanem, Anwar (2007) Self-confidence and its relationship to some variables among students of the College of Education, University of Mosul, Journal of Education and Science, Volume (14), Issue (1), Iraq

17. Al-Washeli, Wadad Ahmad (2007) Selfconfidence and some personality traits among a sample of high school students in Makkah, with an MA thesis, Umm Al-Qura University

18. Al-Zureikat, Ibrahim Abdullah Faraj (2005), Speech and Language Disorders, Diagnosis and Treatment, Dar Al-Fikr, Amman, Jordan, 1st Edition.

19. Arar , Samia . Hashemi, Ikram (2016) Language and Communication Disorders, Diagnosis and Treatment, Journal of Human and Social Sciences, University of Ammar Thleiji, Laghouat, Algeria, Issue 24

20. Baggerly .J\& Max .P ,(2005) child centered groupe play with african boys at the elementary school

21. Bouhouch ,Ammar. Al-Dhiyebat Muhammad Mahmoud (1999) Scientific Research Methods and Research Preparation Methods, University Publications Bureau, Algeria

22. Ender,s. C L (1985) The Impact of peer helper training program on The matunqty and matuty and self-confideme of under graduate student Dissertation Abstrasts Internationa, VOL 42 , NO. 10

23. Haseeb, Muhammad Haseeb (2009) The Effectiveness of a Counseling Program for Developing Self-Confidence and Reducing Stuttering Speech Disorders among Elementary School Children, Unpublished 
Master's Thesis, Cairo, National Center for Examinations and Research

24. Madkour , Ali Ahmed (2006) Teaching Arabic Language Arts, Arab Thought House, Cairo

25. Muhammad, Adel Abdullah (1990) SelfConfidence Scale, The Anglo-Egyptian Library, Cairo

26. Madi ,Naima . Qada , Wahiba (2014), linguistic delay in the child, the elementary stage as a model,, MA thesis, University of Bejaia, Algeria
27. Qawasma, Ahmed. Al-Farah, Adnan (1996) The Development of the Self-Confidence Scale, The Arabic Book for Education, Volume 16, Issue 2, Tunisia

28. Sabra , Fouad (2018) Differences in selfconfidence according to gender, specialization and place of residence, a field study in the College of Education at Tishreen University, Tishreen University Journal for Research and Scientific Studies, Arts and Humanities Series, Volume (40), Issue (1)

29. Shrek, Wizza (2017) Self-confidence and its relationship with motivation to learn among firststage secondary school pupils, Al-Jamea Journal in Psychological Studies and Educational Sciences, 7th Issue, Algeria 